\title{
O elemento castelhano-leonês na formação do Direito Medieval português
}

\section{The Castilian-Leonian element in the formation of Medieval portuguese Law}

\author{
José DOMINGUES \\ Professor Auxiliar da Faculdade de Direito \\ Universidade Lusíada - Porto \\ jdominguesul@hotmail.com
}

Ao mestre, Prof. Doutor Pedro Ortego Gil

(Catedrático de História do Direito da USC)

Recibido: 27 de enero de 2014

Aceptado: 3 de marzo de 2014

\section{RESUMEN}

La autonomía del ordenamiento jurídico del reino portugués, respecto de los reinos cristianos vecinos, no fue, sin duda, el mayor problema durante el período medieval. En los primeros siglos de su existencia heredó la práctica totalidad de las fuentes del Derecho del reino raíz de León. Con el objetivo de adecuarse al movimiento de Recepción del I us commune, desde muy temprano los monumentos legislativos de Alfonso X estuvieron habitualmente presentes en el reino de Portugal. No obstante, con la llegada de la dinastía de Avís comienza la elaboración de un corpus legislativo propio, a través del cual se pretenden abrogar los cuerpos normativos castellanos y mantener cierta autonomía jurídica.

PALABRAS CLAVE: Alfonso X, Partidas, Ordenações, Ordenamiento Jurídico Portugués.

\begin{abstract}
The autonomy of the legal system of the Portuguese kingdom, with respect to the neighboring Christian kingdoms, certainly was not matter of urgency in the medieval period. In the first centuries of his existence he inherited almost all sources of Law from the kingdom mother of Leon. To accompany the movement of Reception of the Ius commune the legislative monuments of Alfonso X were, from very early, usually present in the territory of the kingdom of Portugal. However, with the advent of the dynasty of Avis, starts the development of a proper legislative corpus which aims to abolish the Castilian collections and establish a certain legal autonomy.
\end{abstract}

KEYWORDS: Alfonso the $\mathrm{X}^{\text {th }}$, Partidas, Ordenações, Portuguese Legal System.

\section{RÉSUMÉ}

L'autonomie du système juridique du royaume Portugais envers les royaumes chrétiens voisins n'était certainement pas jugée de toute urgence au cours de la période médiévale. Dans les premiers siècles de son existence, le royaume de Portugal a hérité presque toutes les sources de droit du royaume racine de León. Afin de s'adapter au mouvement de réception du Ius commune, les monuments législatives de 
Alfonso X étaient habituellement présents dans le royaume de Portugal. Cependant, avec l'arrivée de la dynastie Avis, le royaume commence à développer son propre corps législatif, destiné à abroger les corps normatifs Castillans et garder une certaine autonomie juridique.

MOTS CLÉ : Alfonso X, Partidas, Ordenações, système juridique Portugais.

E com estas sentenças sobreditas acordam mujtos direitos E outros a lley iiijo da primeira partida Titollo $x b$.

[Lisboa, BN, Cód. 9.164, fl. 155v]

Seria intento demasiado pretensioso para este trabalho tentar, sequer, ajuizar todo o procedimento formativo e de consequente autonomização do Ordenamento Jurídico português, mesmo que, antecipadamente, em título se limite ao curto espaço temporal da existência medieval do reino de Portugal como realidade jurídico-política independente (desde o século XII ao XV). As breves linhas que se seguem cingir-se-ão a uma breve e sucinta abordagem à relação gerada, neste âmbito, pela vizinhança dos reinos de Leão e Castela (unificados por Fernando III, em 1230). A designação de elemento castelhano-leonês, permitir-me-á essa abordagem em separado dos restantes e sobejamente esfalfados elementos contributivos para a formação do Direito português. Sem olvidar, no entanto, que o contributo daquele, sobretudo a partir da segunda metade do século XIII, muito dificilmente se pode indissociar do elemento mais genérico do ius commune.

A proximidade geográfica, após o processo de independência do reino de Portugal, iniciado no século XII e culminado com o respectivo reconhecimento por parte da Santa Sé através da bula Manifestis probatum de Alexandre III (1179), vai dar origem a uma evidente relação de vizinhança entre estes reinos cristãos. $O$ que não quer dizer que, a partir de então, as relações se tenham pautado sempre pelos cânones da boa vizinhança e amizade mútua, antes pelo contrário, existem momentos de grave crise e tensão política em que se chega a colocar em causa a independência do reino português através de ferinos confrontos bélicos.

Para a temática do elemento castelhano-leonês importa ter bem presente que a sua operacionalidade vai depender de dois vetores distintos, que acabam por convergir no mesmo sentido, para a formação da ordem jurídica portuguesa: por um lado, as boas relações diplomáticas que funcionam como factor de permeabilidade, nomeadamente, através da integração de determinados textos legislativos e aproveitamento de ideais de reforma judiciária; por outro lado, o clima de aberta hostilidade, que irá funcionar como verdadeiro propulsor de uma necessária e reivindicativa autonomia jurídica. Tendo por lastro estes dois critérios basilares, entendi subdividir o estudo em três períodos distintos (i) o período de individualização do Direito português (Séc. XII-1248); (ii) o período de influência das obras jurídicas castelhanas (1248-1385); e (iii) o período de compilação do ius proprium (1385-1446). 


\section{Período de individualização do Direito português (Séc. XII-1248)}

Nos primordiais tempos de independência, o mais sensato é o incipiente reino continuar a reger-se pelo ordenamento jurídico do reino mater. Antes de mais, porque a grande parte dos elementos socio-predominantes se mantém praticamente os mesmos; as alterações marcantes fizeram-se sentir, sobretudo, ao nível da representatividade do poder político e pela imposição de uma nova linha limítrofe imaginária, a separar o território do recém-reino cristão. Também não deixa de ser certo que, a preocupação de conquistar terras ao Corão para alargamento do elemento territorial, deixaria muito pouco tempo sobejo aos primeiros monarcas para criar novas leis. Mas, além do mais, convém não esquecer que, no século XII, ainda estava bastante longe a tradição peninsular (até mesmo europeia) do monarca-legislador.

O perfil típico do monarca dos séculos centrais da Idade Média corresponde a um rei julgador, i.e., conforme asseveram as palavras de Martínez Martínez,

«el rey, como máxima instancia secular, no es un rey legislador, que haga leyes en cuanto que disposiciones generales (ausentes en los primeros siglos medievales). Es, sobre todo, un rey juez, un rey que juzga, cuya forma prototípica de expresión es la sentencia, entendida no como aplicación de leyes previas o de un Derecho anterior, sino como pronunciamento de la Justicia para cada caso concreto, como resolución de cada litigio particular con arreglo a la conciencia jurídica que el monarca encarna o representa, y que finalmente traslada al caso determinado que se le plantea» ${ }^{1}$.

Assim sendo, para a autonomia político-administrativa do incipiente reino português não se tornava imprescindível criar de imediato um novo ordenamento jurídico próprio. Antes pelo contrário, mantiveram-se as fontes de Direito herdadas do reino donde se desmembrara. A nível local, não há qualquer motivo para não perseverar o costume de antigamente arraigado, sendo certo que os concelhos mantiveram os forais pactuados com os monarcas anteriores à independência ${ }^{2}$. A nível geral, mantiveramse as leis antecedentes das cúrias e concílios: uma versão das leis da cúria de Leão (1020) chegou aos nossos dias através do cartulário da Sé de Braga (o chamado Liber Fidei) - mas terão existido outras versões portuguesas diferentes, como se pode deduzir a partir da legislação de D. Afonso II $(1211)^{3}$-, as leis do concílio de Coiança

\footnotetext{
${ }^{1}$ Faustino Martínez Martínez, "Ecos cronísticos del Rey-Juez medieval”, Cuadernos de Historia del Derecho [adiante, CHD], vol. Extraordinário, Madrid, 2010, pp. 319-320.

${ }^{2}$ v. g., os forais outorgados na segunda metade do século XI por D. Fernando I de Leão, o Magno, a S. João da Pesqueira, Penela, Paredes, Linhares e Ansiães, bem como os forais outorgados pelos condes portucalenses e por D. Teresa e D. Afonso Henriques - Cf. Portugaliae Monumenta Historica a saeculo octavo post Christum usque ad quintumdecimum: Leges et Consuetudines [adiante, PMH], Academia das Ciências, Lisboa, 1856-1868, vol. I.

${ }^{3}$ José A. Duarte Nogueira, Lei e Poder Régio I. As Leis de Afonso II, Lisboa, 2006, p. 382, nota 7.
} 
(1055) surgem trasladadas em cartulário da Sé de Coimbra (o chamado Livro Preto) e as leis da cúria de Oviedo (1115) teriam sido juradas por D. Teresa e D. Afonso Henriques ${ }^{4}$.

Duarte Nogueira, ao perscrutar as fontes das leis afonsinas de 1211 confirma e amplia, substancialmente, a influência da legislação curial peninsular no ordenamento jurídico português, atestando que "é pelo menos possível ter a percepção de que na Corte afonsina havia conhecimento em geral das leis leonesas e não apenas das elaboradas nas três assembleias tradicionalmente assinaladas (Leão, Coiança e Oviedo) ". O cotejo de textos permite-lhe inferir o contacto, com variável grau de proximidade, de oito leis portuguesas de Afonso II com leis leonesas anteriores: as leis I e XX com a cúria de 1020; as leis VI, VII, XIV, XXII e XXVII com a cúria de 1188; e a lei XIII com a cúria de 1208. Sem dúvida que a importância das leis de 1188 parece ser claramente superior à das leis das demais cúrias ${ }^{5}$.

O entendimento supra explanando, ajuda à conversão do afastamento português do principal corpus legislativo peninsular coevo - o Código Visigótico, também identificado como Lex Gothorum, Lex Visigothorum, Liber Judicialis, Liber Iudiciorum, Forum Judicum e Liber Judicum - em arcano cada vez mais difícil de solucionar. Ao contrário dos restantes reinos ibéricos, que mantiveram a sua vigência - acabando por ser traduzido para a língua romance, sob a designação de Fuero Juzgo $o^{6}$, por diligência de D. Fernando III de Castela - em Portugal deixa de se aplicar a partir da segunda metade do século XII ${ }^{7}$. Esta circunstância poderá, na minha despretensiosa análise crítica, ser entendida como uma das primeiras atitudes de autonomização jurídica do reino de Portugal, em relação ao reino de Leão.

A resposta para este enigma tem seguido dois plausíveis trilhos: o surgimento e paulatino acentuar do Direito foralengo, por um lado, e o incremento da legislação régia em paralelo com o fenómeno da Recepção do Ius commune, por outro. No entanto, nenhum atinge uma resposta satisfatória e isenta de severo reparo, sobretudo pela dificuldade de harmonização cronológica que ambos suscitam. Determinado o

\footnotetext{
${ }^{4}$ Matéria genericamente aceite e bem conhecida que consta em qualquer manual de História do Direito Português, dispensando qualquer referência bibliográfica.

${ }^{5}$ José A. Duarte Nogueira, Lei e Poder Régio I. As Leis de Afonso II, Lisboa, 2006, p. 382. Cf. anexo IV, coluna 10.

${ }^{6}$ Curiosamente, no inventário dos bens do bispo do Porto, D. Sancho Pires, datado do dia 21 de Junho de 1296, aparece huun livro do Iulgo de Leon (cf. Isaías da Rosa Pereira, "Livros de Direito na Idade Média I", Lusitania Sacra, 1. ${ }^{a}$ série, n. ${ }^{\circ}$ 7, 1964/66, doc. 6); Também no testamento de João Gomes, cónego de Coimbra e reitor da igreja de S. Julião de Portunhos, lavrado no claustro da Sé de Coimbra no dia 27 de Outubro de 1322, aparece uma verba com aliud liber qui est de Foro Legionis (Testamenti Ecclesiae Portugaliae (1071-1325), História Religiosa - Fontes e Subsídios 6, Coord. Maria do Rosário Barbosa Morujão, doc. 2.54, p. 450).

No entanto, o facto de aparecerem estes livros do Fuero Juzgo em bibliotecas medievais privadas não significa que essa colectânea legislativa, ao tempo, tivesse qualquer relevo jurídico-pragmático em Portugal.

${ }^{7}$ José A. Duarte Nogueira, Lei e Poder Régio I. As Leis de Afonso II, Lisboa, 2006, pp. 100-101.
} 
repúdio do Liber na segunda metade do século XII, fica muito além dos primeiros forais em território português (século XI) e muito aquém do big bang da legislação geral dos monarcas portugueses (na segunda metade do século XIII, com D. Afonso III) ${ }^{8}$. Quer um quer outro dos condicionalismos referidos se verificaram no resto da Península Ibérica, não impedindo um conciliar das múltiplas fontes de Direito e a vigência efectiva do Liber Judicum nesses reinos. Até porque tudo indicia que entre a legislação gótica e a foralenga tenha funcionado uma relação de complementaridade e não de antinomia. Os forais, aventa Martínez Martínez,

«en todo momento no agotan toda la materia jurídica, sino que ayudan a completarla. Existe, pues, un cuerpo general o común de derecho (el Liber), auxiliado, completado o suplido por la pléyade de fueros que rigen en cada localidad concreta en algunas materias particulares (nunca de modo absoluto)» ${ }^{9}$.

Em Portugal, o foral de Covas (1166) ${ }^{10}$ e os foros extensos de Alfaiates (confirmados em 1297) ${ }^{11}$ são comprovativo dessa complementaridade, ao consignarem referência expressa para o Código Visigótico.

O cosmos jurídico medieval caracteriza-se pela vigência de uma multiplicidade de fontes em simultâneo, sem réstia de dúvida, uma manta de retalhos com maior preocupação de harmonia do que propriamente de hierarquização de fontes. Pelo que, o desaparecimento precoce do Código Visigótico em Portugal não se pode justificar, de forma imediata e cabal, pelo menos, com o aparecimento e desenvolvimento de distintas fontes do Direito foralengo e comum - ainda por cima, num momento em que o incipiente reino ficava isento da única fonte geral aplicável a todo o seu território. Teria que existir outro argumento assaz coactivo. O que me tem ocorrido, como plausível motivo para o colapso do Liber, pode estar relacionado com o recurso para uma instância jurisdicional suprema, localizada na cidade de Leão - vulgo Fuero de Leon. Quer dizer que, a última instância de recurso para as eventuais dúvidas suscitadas pela aplicação das leis do Liber se situava no âmago do reino de Leão. Assim se entende melhor que, com a revogação do Código Visigótico, no fundo, se pretenderia cortar o cordão umbilical que ligava os súbditos do incipiente reino luso ao Fuero de Leon, através de uma vetusta e arraigada tradição processual de recurso. Por isso, entendo que esta pode ter sido a primordial (ou melhor, uma das primordiais) manifestação de autonomização jurídica do reino de Portugal.

\footnotetext{
${ }^{8} C f$. a exegese crítica de José Artur Duarte Nogueira, Sociedade e Direito em Portugal na Idade Média - Dos Primórdios ao Século da Universidade (Contribuição para o seu Estudo,) Lisboa, 1994, pp. 168189.

${ }^{9}$ Faustino Martínez Martínez, "Antologia de textos forales del Antiguo Reino de Galicia (Siglos XIIXIV)", CHD, n. ${ }^{\circ}$ 10, Madrid, 2003, p. 269.

${ }^{10}$ PMH, Leges, pp. 387-388.

${ }^{11}$ PMH, Leges, p. 486 (rub. 520).
} 
Como ficou dito, os primeiros monarcas lusos legislaram muito pouco. Por referência indirecta de bulas e letras papais sabe-se que D. Afonso Henriques terá feito uma lei sobre as barregãs dos clérigos e o seu filho, D. Sancho I, promulgado uma provisão com características de lei geral. No terceiro reinado, com alguma precocidade no ocidente europeu, D. Afonso II vai promulgar um conjunto de vinte e nove diplomas legislativos, nas Cortes de Coimbra de 1211, e duas no final do reinado. Começar-se-á nesta data a gizar um ordenamento geral próprio, no entanto, o monarca a assumir o relevo de um rei-legislador vai ser D. Afonso III - à semelhança do homólogo castelhano, o seu sogro Afonso X - com uma produção legislativa superior a duas centenas de diplomas. Não é de todo despiciendo que o movimento de Recepção do Ius commune, mesmo que existam alguns indícios antecedentes, se venha a tributar ao reinado deste monarca ${ }^{12}$.

Para manter o fio condutor e o objecto deste estudo, não vamos enveredar pela actividade legiferante dos monarcas portugueses, nem peregrinar pelo inefável fenómeno da Recepção do Ius commune, antes aferrar nas obras jurídicas bafejadas pelo génio jurídico do Afonso Sábio.

\section{Período de influência das obras jurídicas castelhanas (1248-1385)}

O influxo das obras jurídicas castelhanas acaba por se converter num meio privilegiado de penetração do Ius commune no reino de Portugal. A Recepção, como fenómeno bem mais dilatado, já conta com imensos trabalhos de referência ${ }^{13}$. E não

${ }^{12}$ Cf. Ruy de Albuquerque e Martim de Albuquerque, História do Direito Português, vol. 1, Sintra, 2005, pp. 339-341. Fátima Regina Fernandes, "A Recepção do Direito Romano no Ocidente Europeu Medieval: Portugal, um caso de afirmação régia”, História: Questões \& Debates 41, Curitiba, 2004, pp. 73-83.

${ }^{13}$ Um sumário elenco dos trabalhos mais recentes (até ao ano 2000): José Domingues, "Recepção do Ius commune medieval em Portugal, até às Ordenações Afonsinas", Initium 17, 2012, pp. 121-168. Nuno J. Espinosa Gomes da Silva, História do Direito Português - Fontes de Direito, Lisboa, 2011, pp. 189299. Mário Júlio de Almeida Costa, História do Direito Português, com a colaboração de Rui Manuel de Figueiredo Marcos, Coimbra, 2010, pp. 229-381. Fernando José Gautier Luso Soares, Ensaio para a História da Formação do Direito Medieval Português. O elemento romano, 2009. Eduardo Vera-Cruz, Terra de Santa Maria Terra-Mãe do Primeiro Portugal. Estudo de Direito Medieval Hispânico Sobre a Independência de Portugal (1096-1179), vol. II - O Direito, 2007. Ruy de Albuquerque e Martim de Albuquerque, História do Direito Português, vol. 1, Sintra, 2005, pp. 261-334. Paulo Ferreira da Cunha, Joana Aguiar e Silva e António Lemos Soares, História do Direito. Do Direito Romano à Constituição Europeia, Coimbra, 2005 pp. 159-194. Fátima Regina Fernandes, "A Recepção do Direito Romano no Ocidente Europeu Medieval: Portugal, um caso de afirmação régia", História: Questões \& Debates, n. ${ }^{\circ}$ 41, Curitiba, 2004, pp. 73-83. Joana Aguiar e Silva, "A Ciência Jurídica Medieval: Mais do que a Passagem de um Testemunho. O Renascimento Medieval do Direito Romano", Estudos em Comemoração do $10^{\circ}$ Aniversário da Licenciatura em Direito da Universidade do Minho, Coimbra, 2004, pp. 385421. António Manuel Hespanha, Cultura Jurídica Europeia - Síntese de Um Milénio, Sintra, 2003, pp. 89-134. Manuel Augusto Rodrigues, "Note sul «ius commune» in Portogallo", Rivista Internazionale di Diritto Comune, 12, Roma, 2001, pp. 265-287. Marcello Caetano, História do Direito Português (Séc. 
cabe na parametricidade específica deste título, que se limitará a abordar, de uma forma muito breve e sucinta, o fluxo das obras legislativas e doutrinais produzidas, sobretudo, no reinado de Afonso X de Castela. Embora não haja réstia de dúvida quanto ao ressumbrar do labor desses jurisprudentes ducentistas, no espaço geográfico do reino de Portugal, ainda está por apurar o exacto momento cronológico do seu começo. Um dos mais relevantes indícios escritos, da permeabilidade da raia imaginária entre os dois reinos, consta em códice mediévico, sem datação precisa, intitulado Costumes e Foros da Guarda ${ }^{14}$ - que em meados do século XVII aparece sob a custódia da Torre do Tombo ${ }^{15}$.

O elevado interesse, sobretudo histórico-jurídico, que desde muito cedo despertou - e continua a despertar - na atenção dos mais diversos e conceituados investigadores, este cimélio deu origem a múltiplos estudos e sucessivas publicações. Aos costumes do município detentor, acresce o trasladado de algumas leis dos monarcas portugueses, a obra legislativa do Foro Real ${ }^{16}$ e os trabalhos doutrinais dos Nove Tempos dos Pleitos ${ }^{17}$ e das Flores das Leis ${ }^{18}$.

$\mathrm{O}$ facto destes monumentos jurídicos do reino vizinho surgirem num concelho português e vertidos para língua portuguesa, não deixa de ser um indício a levar em

XII-XVI), seguida de Subsídios para a História das Fontes do Direito em Portugal no Séc. XVI, Textos introdutórios e notas de Nuno Espinosa Gomes da Silva, Lisboa/São Paulo, 2000, pp. 333-343.

${ }^{14}$ Lisboa, IAN/TT - Feitos da Coroa, Núcleo Antigo 398; Cód. Ref. ${ }^{a}$ - PT/TT/FC/001/398; em http://digitarq.dgarq.gov.pt/details?id=4182542 (consultado no dia 17 de abril de 2012).

${ }^{15} \mathrm{Cf}$. Fernanda Ribeiro, "Como seria a estrutura primitiva do Arquivo da Casa da Coroa (Torre do Tombo)?", Os Reinos Ibéricos na Idade Média - Livro de Homenagem ao Professor Doutor Humberto Carlos Baquero Moreno, Coordenação Luís Adão da Fonseca, Luís Carlos Amaral e Maria Fernanda Ferreira Santos, Faculdade de Letras da Universidade do Porto e Livraria Civilização, Porto, 2003, p. 1410.

${ }^{16}$ José de Azevedo Ferreira, Afonso X: Foro Real - Edição e estudo linguístico, Instituto Nacional de Investigação Científica, Lisboa, 1987, (2 vol. $\left.{ }^{\mathrm{s}}\right)$. José de Azevedo Ferreira, Afonso X: Fuero Real, Universidade do Minho, Centro de Estudos Portugueses, Braga, 1982. Alfredo Pimenta, Fuero Real de Afonso X, o Sábio, Versão portuguesa do século XIII, publicada e comentada por Alfredo Pimenta, Instituto para a Alta Cultura, Lisboa, 1946.

${ }^{17}$ José de Azevedo Ferreira, "Edição e estudo linguístico dos Tempos dos Preitos", Estudos de História da Língua Portuguesa: Obra dispersa, Colecção Poliedro 7, Universidade do Minho, Centro de Estudos Humanísticos, Braga, 2001, pp. 339-375. Jean Roudil, Jacobo de Junta. Summa de los Nueve Tiempos de los Pleitos. Edition et Etude d'une Variation sur un Thème, Paris, 1986. PMH, Leges I, pp. 330-332. Colecção de Inéditos de História Portuguesa, tomo V, Academia Real das Ciências, Lisboa, 1824, pp. 448-453.

${ }^{18}$ Jean Roudil, La tradition d'écriture des Flores del Derecho, tome I, Paris, 2000, (Anexo 13 de Cahiers d'Etudes Hispaniques Médiévales). Antonio Pérez Martín, "La obra jurídica de Jacobo de las Leys: Las Flores del Derecho", Cahiers de Linguistique Hispanique Médiévale, n. ${ }^{\circ} 22,1998$, pp. 247-270. José de Azevedo Ferreira, Flores de Direito. Edição, estudo e glossário, Universidade do Minho, Braga, 1989. (reeditado em Estudos de História da Lingua Portuguesa: Obra dispersa. Colecção Poliedro 7, Universidade do Minho, Centro de Estudos Humanísticos, Braga, 2001, pp. 415-464). Paulo Merêa, "A versão portuguesa das 'Flores de las leyes' de Jácome Ruiz”, Revista da Universidade de Coimbra, vol. V, Coimbra, 1916, pp. 444-457; e vol. VI, Coimbra, 1917, pp. 341-371. 
linha de conta para a questão da sua aplicabilidade no espaço territorial do reino de Portugal. Mas a verdade é que, até à data, ainda não surgiu qualquer outro facto corroborante, v.g., quaisquer fragmentos ou referências avulsas em documentos coevos. Por isso, mandam os foros da douta cautela que, até lá, se deixe a questão em aberto ${ }^{19}$ - será que estas obras, em algum momento, tiveram efectiva influência no ordenamento jurídico português? Melhor convicção se tem hoje em relação à colectânea legislativa de maior alento do rei Sábio - as Partidas.

Hoje ainda temos um conhecimento muito precário e, o mais certo, é que nunca se consiga desenterrar satisfatoriamente da tumba fria do desconhecido o domínio exercido pelas Partidas de Castela na ordem jurídica portuguesa. De qualquer forma o imperium desta fonte de Direito (independentemente do seu estatuto como fonte imediata ou subsidiária) terá que ser indagado na documentação jurídica remanescente do século XIV e primeira metade do século XV. Para a datação a quo temos que nos bastar com a vetusta tradição, com raízes estendíveis ao século XVII, que aponta a sua tradução para Português ainda no reinado de D. Dinis ${ }^{20}$. Para o reinado seguinte de Afonso IV, a versão portuguesa da Partida Terceira da Torre do Tombo, que venceu o tempo corrosivo até aos nossos dias, confirma uma execução em três meses do ano de 1341 - Era de mil e trezentos e seteenta e noue [1341] quatro dias por andar de Junho [26 de Junho] foy este livro começado. E foy acabado quatro dyas depos San Miguel [3 de Outubro] da era de suso dita e som tres meses mays tres dias. Vasco Lourenço dito Çoudo o escreueo. Deus lhj de boom acabamento ${ }^{21}$. A datação ad quem não é menos ambígua e impenetrável, mas estou convicto que o clima de hostilidade gerado, sobretudo, pela crise da sucessão (1383-1385), que vai impulsionar o procedimento compilatório do Ius proprium, serão, em simultâneo, os dois factores preponderantes para o afastamento das fontes de Direito castelhanas - a tratar infra.

Os testemunhos mediatos da preponderância desta compilação legislativa castelhana podem subdividir-se em três segmentos: (i) os inventários das bibliotecas medievais conhecidos, (ii) os códices e fragmentos, que chegaram aos nossos dias e (iii) os indícios da sua praxis no foro jurídico português, durante a Idade Média.

(i) Dos inventários conhecidos conseguem-se apurar cinco códices das Partidas (maioritariamente, com a versão da Primeira Partida) na biblioteca de D. João I

\footnotetext{
${ }^{19}$ Cf. José de Azevedo Ferreira, Afonso X: Foro Real - Edição e estudo linguístico, Instituto Nacional de Investigação Científica, Lisboa, 1987, vol. I, pp. 101-103. Ruy de Albuquerque e Martim de Albuquerque, História do Direito Português, vol. 1, Sintra, 2005, pp. 141-151.

${ }^{20}$ Esta tradição remonta aos meados do século XVII, na Monarquia Lusitana (1650), de Francisco Brandão. Um documento, sem data, colocado entre outros de D. Dinis, reporta-se explicitamente a uma lei das Partidas (P.1.11.4), a propósito dos casos em que a Igreja não pode dar asilo aos que nela se acolhem - Ordenações Del-Rei Dom Duarte, Edição preparada por Martim de Albuquerque e Eduardo Borges Nunes, Lisboa, 1988, p. 279.

${ }^{21}$ José Azevedo Ferreira, “Terceira Partida de Afonso X: subsídios para a sua edição e estudo”, Estudos de História da Língua Portuguesa: Obra dispersa, Colecção Poliedro 7, Universidade do Minho, Centro de Estudos Humanísticos, Braga, 2001, p. 235.
} 
(1385-1433) e D. Duarte (1433-1438) $)^{22}$, na biblioteca do cenóbio de Santa Maria do Bouro (1437) ${ }^{23}$, na colegiada de Santo André de Mafra $(1474)^{24}$, na igreja de Santiago de Torres Novas $(1538)^{25}$ e no cartório da igreja de Santa Maria do Olival, em Tomar (início do século XVI) ${ }^{26}$.

(ii) Quanto aos códices medievais completos, aos nossos dias chegaram apenas os tomos das Partidas I e III ${ }^{27}$. Entretanto, múltiplos fragmentos tem vindo a ser paulatinamente resgatados à rasoira do tempo. Arthur L-F. Askins, Aida Fernanda Dias e Harvey L. Sharrer elaboram um exaustivo inventário de 21 fragmentos medievais das Partidas de Afonso X; posteriormente, Pedro Pinto acrescenta mais dois fragmentos à Terceira Partida (a que goza de maior representatividade) ${ }^{28}$ :

$$
\begin{aligned}
& \text { Primeira Partida }=2 \text { fragmentos }{ }^{29} ; \\
& \text { Segunda Partida }=7 \text { fragmentos }{ }^{30} ;
\end{aligned}
$$

${ }^{22}$ Livro dos Conselhos de el-rei D. Duarte (Livro da Cartuxa ), edição diplomática de A. H. de Oliveira Marques, João José Alves Dias e Teresa F. Rodrigues, Lisboa, 1982, p. 208.

${ }^{23}$ José Mattoso, "Leituras Cistercienses do Século XV", Religião e Cultura na Idade Média Portuguesa, Obras Completas 9, 2002, pp. 295 e 300: Item huum liuro da primeira partida per lingoajem. Este códice e o de Santa Maria do Olival são traduções portuguesas.

${ }^{24}$ Margarida Garcez Ventura, A Colegiada de santo André de Mafra (Séculos XV-XVIII), Mafra, 2002, p. 25: "Item (...) da partida".

${ }^{25}$ Isaías da Rosa Pereira, "Dos livros e dos seus nomes. Bibliotecas litúrgicas medievais", Arquivo de Bibliografia Portuguesa, 17/63, Coimbra, 1971-1973, pp. 127 e 165: "Item huma Partida, a primeira". ${ }^{26}$ Pedro Pinto, "Inventário Quinhentista das Igrejas de Santa Maria do Olival, São João da Praça, Santa Maria do Castelo, Santa Iria, Santa Maria das Pias, e da Ermida de Santa Maria do Monte", Revista de Artes Decorativas 4, 2010, 167-175: Jtem outro liuro per lingoajem da primeira partida e no cabo com hum tractado de sancto agostinho. O inventário de 1510 desta igreja, publicado por Isaías da Rosa Pereira dá conta apenas das Decretais de Gregório IX, mas não refere o livro das Partidas - cf. Isaías da Rosa Pereira, "Achegas para a História da Cultura Jurídica em Portugal”, Boletim da Faculdade de Direito da Universidade de Coimbra. Estudos em Homenagem aos Profs. Doutores M. Paulo Merêa e G. Braga da Cruz, 58-2, Coimbra, 1982, pp. 511-528.

${ }^{27}$ Lisboa, BN - Alc. 463 e Lisboa, IAN/TT - Leis e Ordenações, Núcleo Antigo, n. ${ }^{\circ}$ 3. Publicado apenas a Primeira Partida - Alphonse X Primeyra Partida, Édicion e Étude de José de Azevedo Ferreira, Textos de Linguística 3, INIC, Braga, 1980.

${ }^{28}$ Arthur L-F. Askins, Aida Fernanda Dias e Harvey L. Sharrer, Fragmentos de Textos Medievais Portugueses da Torre do Tombo, Instituto dos Arquivos Nacionais / Torre do Tombo, Lisboa, 2002. Pedro Pinto, "Um novo fragmento português medieval da Terceira Partida de Afonso X", Boletim da Direcção-Geral de Arquivos, n. ${ }^{\circ}$ 8, Janeiro-Março 2009, p. 5.

Pedro Pinto localizou mais um fragmento da Terceira Partida na Biblioteca da Sociedade Martins Sarmento (Guimarães), B. S. - 1-7-94. Capa do Livro das notas de Salvador de Faria, cavaleiro fidalgo da Casa de El-rei Nosso Senhor, tabelião do público judicial da vila de Guimarães e seu termo, de 1554.

${ }^{29}$ Lisboa, IAN/TT - Santa Cruz de Coimbra, pasta 41, doc. s/n; Lisboa, IAN/TT - Colegiada de Santa Iria de Santarém, n. ${ }^{\circ} 1$.

${ }^{30}$ Coimbra, AU - D. ${ }^{\circ}$ V-3 $3^{\mathrm{a}}$-S-Móvel 9-g-7 (1); Coimbra, AU - D. ${ }^{\circ}$ V-3 ${ }^{\mathrm{a}}-\mathrm{S}-\mathrm{Móvel}$ 9-g-7 (2); Braga, AD - Fragmento, pasta 5, n. ${ }^{\circ}$ 233-A; Braga, AD - Fragmento, pasta 5, n. ${ }^{\circ}$ 233-B ; Braga, AD - Fragmento, pasta 5, n. ${ }^{\circ}$ 234; Lisboa, IAN/TT - Gate 7, mç. 15, n. ${ }^{\circ} 2$ (capa); Nova Iorque, HSA - B, 1570. 
Terceira Partida $=10$ fragmentos ${ }^{31}$

Quarta Partida = (não se conhece qualquer fragmento);

Quinta Partida $=1$ fragmento $^{32}$

Sexta Partida $=1$ fragmento (quatro pequenas tiras de pergaminho) ${ }^{33}$;

Sétima Partida $=2$ fragmentos ${ }^{34}$.

(iii) A preponderância directa ${ }^{35}$ das Partidas na praxis medieval portuguesa, até onde me foi possível averiguar, pode resumir-se a cinco items fundamentais: (a) uma precoce integração legislativa, a propósito do direito de asilo em território sagrado das igrejas cristãs, de uma lei da Primeira Partida (P.1.11.4) em diploma do reinado de D. Dinis ${ }^{36}$; (b) as queixas dirigidas a el-rei D. Pedro I, pelo clero e pelos estudantes da Universidade de Coimbra, contra o uso generalizado e excessivo das Partidas, em detrimento, respectivamente, do Direito canónico e do Direito romano ${ }^{37}$; (c) a salvaguarda das leis que integram o título dos Reptos da Sétima Partida (P.7.3) em carta de legitimação dos filhos do clérigo Lopo Rodrigues ${ }^{38}$; (d) a menção expressa, lado a lado com as outras fontes de Direito vigentes, a todos os livros das Partidas nas cartas de quitação (v. g., 1430.Dezembro.15, 1456.Março.06, 1460.Outubro.20) ${ }^{39}$ (e)

${ }^{31}$ Lisboa, IAN/TT - Espólio Silva Marques, Pasta 01; Braga, AD - Fragmento, pasta 5, n. 235 e 236 ; Braga, AD - Fragmento, pasta 5, n. ${ }^{\circ}$ 240; Braga, AD - Fragmento, pasta 5, n. ${ }^{\circ}$ 233-C; Braga, AD - Fragmento, pasta 5, n. ${ }^{\circ}$ 241; Coimbra, Dr. Adelino Esteves Santos; Braga, Arquivo Paroquial de S. João do Souto - Fragmentos pergamináceos, 1; Braga, Arquivo Paroquial de S. João do Souto - Fragmentos pergamináceos, 2; Lisboa, IAN/TT - Mosteiro de Santa Cruz de Coimbra, 2. a Incorporação, mç. 236; Guimarães, BSMS - B. S. - 1-7-94.

${ }^{32}$ Lisboa, IAN/TT - Fragmentos, Cx. 21, n. 3.

${ }^{33}$ Lisboa, MNA-LV - sem cota.

${ }^{34}$ Coimbra, AU - D. ${ }^{\text {V V-3 }}$-S-Móvel 9-g-7 (3); Évora, BP - Fragmentos, Pasta 4, n. ${ }^{\text {a }} 2$.

${ }^{35}$ Indirectamente, no Livro de Leis e Posturas e no próprio códice das Partidas (Livro III), preservado na Torre do Tombo, ficaram registadas notas marginais e remissões para os livros das Partidas. [cf. José Anastácio de Figueiredo, "Memoria sobre qual foi a época da introducção do Direito de Justiniano em Portugal, o modo da sua introducção, e os gráos de authoridade, que entre nós adquirio. Por cuja occasião se trata a importante materia da Ord. liv. 3 tit. 64", Memorias de Litteratura Portugueza, Academia Real das Ciências de Lisboa, tomo I, Lisboa, 1792, p. 284; Livro das Leis e Posturas, Prefácio de Nuno Espinosa Gomes da Silva e leitura paleográfica e transcrição de Maria Teresa Campos Rodrigues, Lisboa, 1971; Isabel Beceiro Pita, "Notas sobre la influencia de «Las Siete Partidas» en el reino Portugués", Os Reinos Ibéricos na Idade Média, Livro de Homenagem ao Professor Doutor Humberto Carlos Baquero Moreno, Coordenação de Luís Adão da Fonseca, Luís Carlos Amaral e Maria Fernanda Ferreira Santos, Faculdade de Letras da Universidade do Porto e Livraria Civilização, Porto, 2003, pp. 487-499]

${ }^{36}$ Ordenações Del-Rei Dom Duarte, Edição preparada por Martim de Albuquerque e Eduardo Borges Nunes, Lisboa, 1988, p. 279.

${ }^{37}$ Guilherme Braga da Cruz, "O Direito Subsidiário na História do Direito Português", Obras Esparsas: Estudos de História do Direito. Direito Moderno, vol. II, 2. ${ }^{a}$ Parte, Coimbra, 1981, pp. 280-282, nota 1. ${ }^{38}$ Lisboa, IAN/TT - Chancelaria de D. Fernando, Liv. 2, fls. 92-92v.

${ }^{39}$ Chancelaria de D. Duarte, vol. II (Livro da Casa dos Contos), Centro de Estudos Históricos - Universidade Nova de Lisboa, Lisboa, 1999, doc. 41, p. 74; Documentos das Chancelarias Reais anteriores a 1531 relativos a Marrocos, publicados por ordem da Academia Real das Ciências de Lisboa e sob a 
a invocação de duas leis da Terceira Partida (P.3.7.15 e P.3.2.29) em processo judicial que correu termos na vila de Alcácer do Sal, entre os finais de 1396 e os princípios de $1397^{40}$.

Outra fonte de Direito, desconhecida para a bibliografia hodierna, mas assiduamente referenciada nas legitimações do século XIV é a do costume dos fidalgos de Espanha. D. Afonso IV, no dia 6 de Junho de 1338, legitima Vasco Martins Leitão, não embargando o costume dos filhos dalgo de Espanha ${ }^{41}$. Nas legitimações do seu sucessor, D. Pedro I, mantém-se a cláusula de exclusão, mais ou menos, nos seguintes termos: $e$ outrossy nom embargando custumes dos fidalgos da espanha que defendem aos assy nados que nom possam djzer nem meter mãos a qual ley e custumes tolho e nom quero que aiam lugar em este ${ }^{42}$. Esta técnica de isentar os filhos legitimados (por carta régia) do costume dos fidalgos de Espanha estende-se por todo o reinado de D. Fernando ${ }^{43}$. No entanto, após a crise da sucessão, salvo rara excepção (que copie o formulário das cartas anteriores a 1383), é suprimida esta cláusula das cartas de legitimação.

direcção de Pedro de Azevedo, Tomo II (1450-1456), Lisboa, 1934, doc. 313, p. 331; Lisboa, IAN/TT - Leitura Nova, Liv. 37, fls. 59-59v (Livro dos Extras).

${ }^{40}$ Militarium Ordinum Analecta 7. Fontes para o estudo das Ordens Religioso-Militares. Livro dos Copos, 2006, doc. 130, pp. 248-256.

O documento, no início, está datado da Era de mil e quatrocentos e trinta e tres annos, correspondente ao ano de 1395. Deve ter sido erro do compilador do Livro dos Copos, porque a era que se adequa à cronologia de todo o processo é a de mil quatrocentos e trinta e quatro (= ano de 1396). Caso contrário, a iniciar-se em 1395, teríamos um vácuo injustificável para o ano de 1396. Por outro lado, a procuração de Maria Gonçalves ao seu procurador, Gomes Eanes, é do dia 6 de Novembro da Era de mil e IIIIc $X X X$ $I I I I^{\circ}$ annos (= ano de 1396). Por isso, só podem ser posteriores a essa data os actos praticados por este procurador em nome da dita Maria Gonçalves. O que quer dizer que a parte que nos chegou deste processo judicial se desenrolou, em Alcácer do Sal, nos meses finais de 1396 (Novembro e Dezembro) e primeiro de 1397.

Este documento veio responder afirmativamente à questão em aberto, sobre a aplicabilidade das Partidas nas instâncias jurídicas portuguesas, legada por José de Azevedo Ferreira, "Terceira Partida de Afonso X: subsídios para a sua edição e estudo", Estudos de História da Língua Portuguesa: Obra dispersa, Braga, 2001, p. 246. Cf. também Isabel Beceiro Pita, "Notas sobre la influencia de «Las Siete Partidas» en el reino Portugués”, Os Reinos Ibéricos na Idade Média, Porto, 2003, p. 491: «El conjunto de las diversas anotaciones y documentos recogidos en este manuscrito lleva a pensar que, con toda probabilidad, Las Siete Partidas no funcionaron en Portugal como una normativa utilizada en primera instancia».

${ }^{41}$ Chancelarias Portuguesas - Chancelaria de D. Afonso IV, Vol. II (1336-1340), Instituto Nacional de Investigação Científica / Centro de Estudos Históricos da Universidade Nova de Lisboa, Lisboa, 1992, doc. 110 .

${ }^{42}$ Chancelaria D. Pedro I (1357-1367), Instituto Nacional de Investigação Científica / Centro de Estudos Históricos da Universidade Nova de Lisboa, Lisboa, 1984, doc. 110 (1357.Agosto.26), que se repete nos doc. 116 (1357.Agosto.26), 592 (1361.Setembro.12), 840 (1361.Junho.24) e 1036 (1365.Agosto.29). ${ }^{43}$ V. g., Lisboa, IAN/TT - Chancelaria de D. Fernando, Liv. 1, fls. 17-17v (1367.Setembro.16); Liv. 1, fls. 29v-30 (1367.Outubro.15); Liv. 2, fls. 67-67v (1370.Março.02); Liv. 1, fls. 60-60v (1370.Maio.18); Liv. 2, fls. 12v-13 (1377.Agosto.10); Liv. 2, fls. 37v-38 (1379.Fevereiro.04); Liv. 2, fls. 43-43v (1379.Abril.29); Liv. 2, fls. 82-82v (1381.Maio.30). 
Esta supressão foi, com certeza, ditada pela aversão que passou a ser tributada às fontes de Direito castelhanas e pelo raiar das primeiras compilações de Ius proprium portuguesas, como se dirá de imediato. No entanto, antes de encerrar este período, uma breve palavra às reformas judiciárias encetadas no reinado de D. Afonso III, acalentadas pelas do reino vizinho. Tudo indica que a reforma da justiça, empreendida por Afonso III de Portugal ${ }^{44}$, possa ter sido contagiada pela que Afonso X prosseguia em Castela. Pelo menos, no que concerne à substituição dos dois meirinhos régios de Além e Aquém-Douro por um único meirinho-mor de Portugal (Nuno Martins de Chacim, circa 1261), a analogia é demasiado álgida para se não detectar mais uma permeabilidade na organização jurídico-territorial do reino adoptada, sobretudo a partir de 1258, por Afonso $X^{45}$. Mais tarde, em pleno curso do século XIV, a influência dos corregedores de comarca (magistrados sucessores dos meirinhos-mores) far-seá sentir em sentido contrário. Ou seja, o corregidor castelhano terá sido criado (a sua primeira referência normativa fiável continua a ser a das Cortes de Alcalá de Henares de 1348) por influência do homólogo português ${ }^{46}$.

\section{Período de compilação do Ius proprium (1385-1446)}

Reitero - cada vez mais convicto - que a sucessão dinástica (que sepultou a dinastia Afonsina e fez emergir a de Avis) e a grave crise da independência acalentaram o sentimento agudo de que seria necessária e urgente uma independência jurídica de Portugal, face às fontes jurídico-legislativas do reino vizinho (maxime às Partidas), que grassavam pelo reino ${ }^{47}$. Como seria de esperar para o tempo que corria no século $\mathrm{XV}$, ainda muito adverso a mudanças jurídicas bruscas e radicais, o afastamento das fontes castelhanas terá passado por um processo moroso de transição, acalentado na Corte e, paulatinamente, propagado aos diversos recantos do reino. Não surpreende, por isso, que em data posterior à crise de 1383-1385 e à existência de códices de Ius

\footnotetext{
${ }^{44} C f$. Leontina Ventura, A Nobreza da Corte de Afonso III, Dissertação de Doutoramento apresentada à Universidade de Coimbra, vol. I, Coimbra, 1992, p. 97 e pp. 485 e ss.

${ }^{45}$ José Domingues, "Os Primórdios do Ius Corrigendi em Portugal: Os Meirinhos-mores de D. Afonso III", Revista Lusíada - Direito, n. ${ }^{\text {os }} 1$ e 2, Porto, 2011, p. 185.

${ }^{46}$ Agustin Bermúdez Aznar, El Corregidor en Castilla durante la Baja Edad Media (1348-1474), Murcia, 1974, pp. 57-58; José Sánchez-Arcilla Bernal, "Algunas consideraciones acerca del origen de los corregidores en Portugal y en España”, en Justicia y Derecho tributario: libro homenaje al profesor Julio Banacloche Pérez (coord. por Carmen Banacloche Palao, Julio Banacloche Pérez-Roldán y Begoña Banacloche Palao), Madrid, 2008, pp. 801-820.

O primeiro regimento do corregedor português está datado do ano de 1332, mas o problema da sua origem ainda não encontrou uma solução definitiva. $C f$. o que a este propósito deixei expresso em José Domingues, "Dos Meirinhados às Comarcas Medievais Portuguesas", Initium 14, Barcelona, 2009, pp. 218 e ss.

${ }^{47}$ Cf. José Domingues, As Ordenações Afonsinas - Três Séculos de Direito medieval (1211-1512), Zéfiro Editora, Sintra, 2008, p. 58, em http://docentes.por.ulusiada.pt/jdomingues/work/ordenacoesafonsinas.pdf (consultado dia 25 de abril de 2012).
} 
proprium se continue a utilizar a colecção das Partidas de Castela, v. g., no processo de Alcácer do Sal (1396/97) ${ }^{48}$ e nas cartas de quitação de 1430, 1456 e $1460^{49}$.

Os legisperitos próximos do monarca vitorioso (particularmente o Doutor João das Regras), cônscios de que o intuito de afastar as fontes de Direito castelhanas iria deixar um vácuo jurídico difícil de preencher, são compelidos para a tradução de textos legais ${ }^{50}$ e para a compilação do sistema português de Ius proprium. Encetaram uma obra considerada, ao tempo, pioneira no panorama jurídico-mediévico da Europa ocidental. A corrente historiográfica hodierna, sem ressalvas, identifica essa obra oficial, iniciada pelo monarca da Boa Memória, com a conclusão das Ordenações Afonsinas (Arruda, 1446), remetendo o Livro de Leis e Posturas e as Ordenações de D. Duarte para o catálogo das compilações privadas ${ }^{51}$.

O meu entendimento tem-se vincado em torno da existência de colectâneas oficiais de Ius proprium muito antes das Afonsinas $^{52}$. De forma muito rápida e sucinta, até à data, a primeira referência documental a um livro oficial de leis da Chancelaria de D. João I surge em carta testemunhável remetida ao arcebispo de Braga, com a ordenação de el-rei D. Fernando de 18 de Setembro de 1368. O monumento da lavra de D. João I, assinado em Coimbra no dia 7 de Abril de 1390, antes de trasladar a lei fernandina, consigna uma referência explícita ao correspondente livro das leis, assim: Dom Joham pella graça de deus Rey de portugall e do algarue Aa quantos esta carta virem fazemos saber que dom lourenço arçebispo de bragaa nos disse que no liuro das leix da nosa chancellarya era scripta huma lex que foy fecta per El Rey dom fernando nosso Jrmaão a que deus perdooe da qual o teor tal lhe ${ }^{53}$. A data deste docu-

\footnotetext{
${ }^{48}$ Militarium Ordinum Analecta 7. Fontes para o estudo das Ordens Religioso-Militares. Livro dos Copos, 2006, doc. 130, pp. 248-256.

${ }^{49} \mathrm{Cf}$. a identificação supra, na nota 39 .

${ }^{50}$ Hoje está acreditado o vetusto mito que, desde Duarte Nunes de Leão, tributa a tradução para Português do Código de Justiniano, com a Glosa de Acúrsio e a Opinião de Bártolo, ao Doutor João das Regras [cf. Guilherme Braga da Cruz, "O direito subsidiário na história do direito português", Obras Esparsas, vol. II 2. ${ }^{\text {P }}$ Parte, Coimbra, 1981, pp. 291-293].

Sobre as políticas de tradução empreendidas pela dinastia de Avis, que se estende aos principais centros culturais do séc. XV, cf. Saul António Gomes, "As politicas culturais de tradução na corte portuguesa no século XV", Cahiers d'Études Hispaniques Médiévales, n. ${ }^{\circ} 33$, 2010, p. 173-181, em http://www.persee.fr/web/revues/home/prescript/article/cehm_1779-4684_2010_num_33_1_2239 (consultado no dia 5 de maio de 2012).

Nas palavras deste autor: «traduzir é, entre os Príncipes de Avis, e não apenas para a transposição do latim no português, tanto um acto de sublime amor pelas humaniores litterae, quanto um serviço à res publica, aos portugueses, cuja língua pátria, por viva, suplantava o latim dos antigos autores».

${ }^{51}$ Não é o momento apropriado para versar sobre a qualificação destas obras como colectâneas privadas, saliente-se, no entanto, que, até à data, se trata de decisão conjectural, sem qualquer prova documental segura e fiável.

${ }^{52}$ Espero, em breve, publicar um trabalho já concluído, com os caboucos documentais que me permitem sustentar este parecer, que venho defendendo há algum tempo.

${ }^{53}$ Braga, AD - Colecção Cronológica, doc. 902.
} 
mento aproxima-se das Cortes de Coimbra de 1385, plausivelmente, o berço da primeira compilação legislativa portuguesa.

A partir daqui, nos próximos cinquenta e seis anos que nos separam da conclusão das Afonsinas, pode dizer-se que (ultrapassando a meia centena) não são raras as alusões que a documentação, que chegou até nós, tributa aos livros de Leis ou livros de Ordenações. Para além do número bastante expressivo, as menções documentais estão sempre associadas a monumentos legislativos gerais portugueses: leis do monarca, capítulos de cortes e concordatas. Numa dessas conjunturas, com o acordo do seu Conselho, o monarca fixa interpretação autêntica para harmonizar o conteúdo de duas leis de reinados anteriores. Sem esquecer que esses documentos são dirigidos aos mais altos dignatários do reino, com subida responsabilidade na administração da justiça - por que se entendia [arcebispo, bispo, concelho, cidade, vila, mestre] della ajudar -, muitos deles conhecidos em original, que ainda preserva o selo régio ou seus vestígios. Em conclusão, o monarca no exercício das suas funções, nomeadamente na de administrar a justiça, nunca usa livros privados; seria estultice acreditarmos que, em tempos de acérrimo combate às falsificações documentais, se assinassem e asselassem diplomas régios com traslados feitos a partir de um livro privado de Ordenações.

A esta primeira tentativa compilatória (que deve ter produzido dois livros, um com a legislação até D. Afonso IV e outro com a posterior) acresce uma nova fase que, a partir das Cortes de Santarém de 1418, terá originado um novo livro de Ordenações. Em resumo, neste momento, entendo que já estariam em vigor livros de Ordenações em 1390, a que acresceu outro livro de Ordenações em 1418, sendo que a compilação das Afonsinas (que veio revogar os livros anteriores) só se terá iniciado - após a tentativa falhada nos finais do reinado de D. João I - no início do reinado de D. Duarte (1433). Não será de todo despiciendo que, os livros das Ordenações Afonsinas (designação moderna), durante o período da sua vigência efectiva, tenham sido conhecidos como livros da reforma das Ordenações. Por outras palavras, se o primeiro sistema compilatório produziu livros de Ordenações, parece óbvio que o segundo sistema tenha dado origem aos livros da reforma das Ordenações ${ }^{54}$.

Com o impulso da crise da independência e das Cortes de 1385, a incipiente compilação do Ius proprium assume o importante papel de garante primordial da autonomia do ordenamento jurídico português, face ao vizinho de Castela. No entanto, o golpe de misericórdia vai ser disferido pelas Ordenações Afonsinas (pese embora, as cartas de quitação de datação posterior a 1446 com menção explícita às Partidas - provavelmente, o sobejo de formulários antecedentes, desfasados com a coetânea

\footnotetext{
${ }^{54}$ Cf. José Domingues, As Ordenações Afonsinas - Três Séculos de Direito medieval (1211-1512), Sintra, 2008, em http://docentes.por.ulusiada.pt/jdomingues/work/ordenacoesafonsinas.pdf (consultado dia 10 de abril de 2012); "A Última Reforma do Direito Medieval Português", Revista Lusíada - Direito, Série I n. ${ }^{\text {os }} 1$ e 2, Porto, 2010, pp. 359-437; Códices Medievais de Ius Proprium em Portugal (no prelo).
} 
realidade jurídica). No título $9^{\circ}$ do livro II desta colectânea legislativa de origem portuguesa - terminada durante a regência do infante D. Pedro, na menoridade de D. Afonso $\mathrm{V}$ - ficam identificadas e definidas as múltiplas fontes do Direito que fazem parte da coeva ordem jurídica portuguesa: como fontes imediatas a lei do reino, o costume antigo do reino e os estilos da Corte; as fontes aplicáveis a título subsidiário, na falta das primeiras, são o Direito romano, o Direito canónico, a Glosa de Acúrsio, a Opinião de Bártolo e, por último, o recurso à decisão do monarca ${ }^{55}$.

A exclusão das obras jurídicas castelhanas, latente desde os finais do século XIV, torna-se bem álgida e patente a partir da reforma das Ordenações ou Ordenações Afonsinas. No entanto, considero estar longe de ter terminado aqui a influência das Partidas. Embora o compilador português o não admita de forma manifesta, fez proveito dos textos legislativos das Partidas de Afonso X para a composição de títulos da sua obra. Como alguns desses títulos se transmitem às sucessivas Ordenações Manuelinas $\left(1512 / 13,1514\right.$ e 1521) ${ }^{56}$ e Filipinas (1603), o elemento castelhano irá perpetuar-se na formação do ordenamento jurídico português até ao movimento codificador do século XIX, pelo menos. A 'nacionalização' dos textos jurídicos castelhanos das Partidas, revelada há séculos ${ }^{57}$, ainda não está suficientemente estudada, mas terá que ficar adiada para fôlego futuro.

\footnotetext{
${ }^{55}$ Ordenações Afonsinas, Liv. II, Tít. $9^{\circ}$ [consultei Ordenações Afonsinas, Fundação Calouste Gulbenkian, Lisboa 1984. Fac-simile a partir da edição das Ordenaçoens do Senhor Rey D. Affonso V, Real Imprensa da Universidade, Coimbra, 1792, pp. 161-164].

${ }^{56}$ Muito recentemente apareceram fragmentos de uma edição desconhecida das Manuelinas, intercalada entre a de 1514 e a de 1521.

${ }^{57} \mathrm{O}$ primeiro autor a chamar a atenção da influência das Partidas na composição das Afonsinas foi José Veríssimo Alvares da Silva, Introdução ao novo codigo, ou dissertação critica sobre a principal causa da obscuridade do nosso codigo authentico, na Regia Officina Typografica, Lisboa, 1780, p. 18, nota 1. A identificação, em concreto, de alguns títulos em que a fonte das Afonsinas foram as Partidas de Castela, deve ser tributada a Henrique da Gama Barros, História da Administração Pública em Portugal nos séculos XII a XV, tomo I, Lisboa 1885, p. 127.
} 